\title{
Web based Institutional Repository Futuristic Approach: A Model in Anna University of Technology Tirunelveli
}

\author{
Mr.V.Srinivasan ${ }^{1}$, Dr.K.Vinitha ${ }^{2}$, \\ Research Scholar, M.S. University, Tirunelveli, \\ Librarian, St. Mary's College, (Autonomous) College,
}

\begin{abstract}
The term "Repository" does not simply mean one of the software tools discussed later. Repository library is present trend of collecting the academic and research oriented literature available on the web. This article is narrates the web based institutional repository and to initiate the concept at academic institution 'A model study of Anna University of Technology Tirunelveli' for the benefit of faculty and research scholars. Now a day the knowledge explosion is uncontrollable at the same time new ideas concepts are scattered. As such to capture and preserve the literature may be descriptive or on multimedia is the progressive trend in the IT environment. Institutional Repositories contain a wealth of information which could benefit from the application of this technology. The tool used for Establish the Web base Institutional Repositories is "Space" software. The Institutional Repository uses the Space Open source digital library software (OpenOffice.org) developed jointly by the Massachusetts Institute of technology libraries and Hewlett-Packard (HP). It is freely available for research institutions worldwide as an open source system. Material in this repository includes Theses, Projects Reports, Annual Reports etc.. This article gives an idea to initiate the web based repositories in Higher learning Institutions.
\end{abstract}

Key word: Institutional Repository, Open access, Higher learning Institutions, Hardware

\section{Introduction:}

An Institution Repositories is a digital collection of an institution's intellectual output. It provides a web based mechanism for researcher to depositing the digital material and access their research publications. The repositories of AUTT collects, preserves and makes available in digital format the scholarly output of the AUTT community which contains 150 faculty, 320 employees and 1300 students. The interface of the IR provides for essay self-archiving by faculty, and organists the documents in a logical and easily retrievable fashion. Digital collections in IR capture and preserve the intellectual output of university communities. Now a day many academic libraries are migrating to digital library. Web based Institutional Repository is expected with technology and process improvements for digital collection. Higher learning institutions are very interest in establishing institutional repositories. The use of student community is identified as a key factor in establishment of institutional repository. Best practices and recommendations for future developments such as early stakeholder groups and the need to educate both librarians and faculty about open access collections are also discussed in this article. This study contributes how to establish the web based institutional repositories in higher learning institutions.

\section{Benefits of Institutional Repositories:}

Repository can interoperate with other university systems and maximise efficiencies between them by sharing information a repository can increase the visibility and prestige of institution depending on content contained. Repository content is readily searchable both locally and globally allows an institution to manage their intellectual property by raising awareness of copyright issues and facilitating the recording of relevant rights information. A repository that contains high quality content could be used as shop window or marketing tool to entice faculty, staff and students funding. Repositories can store other types of content that is not necessarily published, sometimes known as "grey literature". Repositories may be an important tool in managing an institution's research assessment or quality assessment submission. Repositories could provide cost savings in the long run provided that a significant amount of content is deposited in them, it offers greater flexibility over websites with better security and preservation of various kinds of digital materials through the collection of standardise metadata about each item.

\section{Software for Institutional Repository's}

For establishing institutional repositories many open source software are available on public domain. The most widely used are : GSDL (green stone digital library), Eprints, Dspace, Fedora, Ganesha, VITAL, Alexandria, dLibra, MiTOS ETD-db(electronic Theses and Dissertations database), CDSware and many more 
software's have different features for building the institutional repositories. To design an institutional repository the institution has to select the software according to their need and purpose.

III. Comparative study of Institutional Repository:

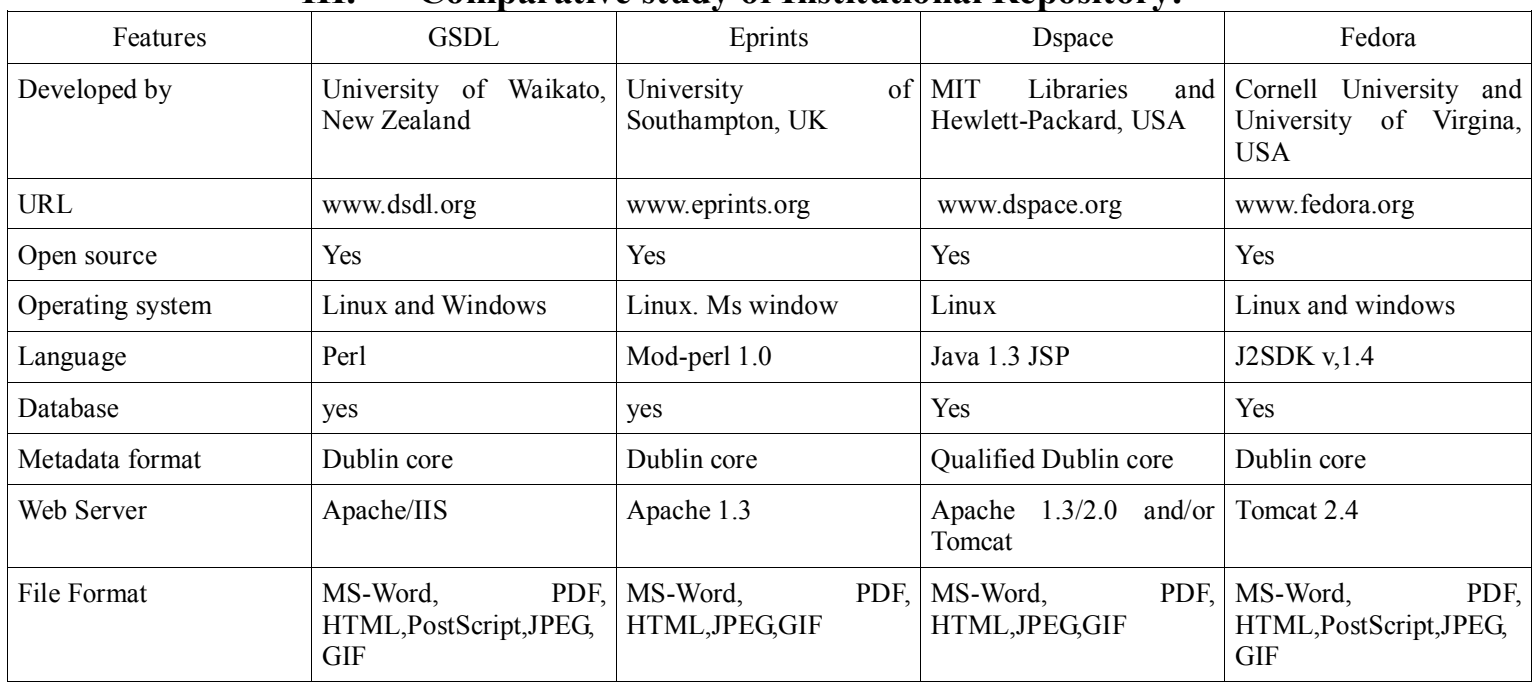

Table:1 The institutional repositories in India is gaining popularity and majority of the science and technology university libraries and information centres are involved in creating such services in higher learning institutions.

\begin{tabular}{|c|c|}
\hline Name of the institution repositories & IR Used \\
\hline ARIES, Digital Repository & Dspace \\
\hline DeepBlue Knowledge Repository@PDPU & Dspace \\
\hline Delhi College of Engineering Repository & Dspace \\
\hline Dhananjayarao Gadigil Library & Dspace \\
\hline Digital Knowledge Repository of Central Drug Research Institute & Dspace \\
\hline Digital Library at Indian Statistical Institute, Bangalore & Dspace \\
\hline Digital repository of Cochin University of Science \& Technology & Dspace \\
\hline Digital repository of West Bengal Public Library Network & Dspace \\
\hline DigitalLibrary@CUSAT & Dspace \\
\hline DRS at National Institute Of Oceanography & Dspace \\
\hline DSpace@GGSIPU & Dspace \\
\hline dspace@sdmcet & Dspace \\
\hline DSpace at IBS Ahmedabad & Dspace \\
\hline Dspace at IIT Bombay & Dspace \\
\hline DSpace at Indian Institute of Management Kozhikode & Dspace \\
\hline DSpace at IUCAA & Dspace \\
\hline DSpace at M S University & Dspace \\
\hline DSpace at NCRA & Dspace \\
\hline DSpace at Vidyanidhi & Dspace \\
\hline DSpace@IMSC & Dspace \\
\hline DSpace@INFLIBNET & Dspace \\
\hline Dspace@NITR & Dspace \\
\hline DSpace@TU & Dspace \\
\hline eGyankosh & Dspace \\
\hline Electronic Theses and Dissertations at Indian Institute of Science & Dspace \\
\hline EPrints@IITD & Dspace \\
\hline IACS Institutional Repository & Dspace \\
\hline
\end{tabular}




\begin{tabular}{|c|c|}
\hline IIT Roorkee Repository & Dspace \\
\hline Indian Institute of Astrophysics Repository & Dspace \\
\hline Indian Institute of Petroleum Institutional Repository & Dspace \\
\hline $\begin{array}{l}\text { Institutional Repository of Intectual Contributions of Delhi } \\
\text { Technological University }\end{array}$ & Dspace \\
\hline Institutional repository@VSL & Dspace \\
\hline Kautilya Digital Repository at IGIDR & Dspace \\
\hline Knowledge Repository of Indian Institute of Horticultural Research & Dspace \\
\hline Knowledge Repository Open Network & Dspace \\
\hline Librarians' Digital Library & Dspace \\
\hline Management Development Institute - Open Access Repository & Dspace \\
\hline National Science Digital Library & Dspace \\
\hline NISCAIR Online Periodical Repository & Dspace \\
\hline Osmania University Digital Library [OUDL] & Dspace \\
\hline Raman Research Institute Digital Repository & Dspace \\
\hline ShodhGanga: A reservoir of Indian theses & Dspace \\
\hline Vidya Prasarak Mandal - Thane & Dspace \\
\hline Catalysis Database & EPrints \\
\hline CMFRI Digital Repository & EPrints \\
\hline DIR@IMTECH & EPrints \\
\hline DU Eprint Archive & EPrints \\
\hline Eprint@NML & EPrints \\
\hline Eprints@MDRF & EPrints \\
\hline Eprints@IARI & EPrints \\
\hline ePrints@NII & EPrints \\
\hline Eprints@SBT MKU & EPrints \\
\hline Etheses - A Saurashtra University Library Service & EPrints \\
\hline ICRISAT Open Access Repository & EPrints \\
\hline Indian Academy of Sciences: Publications of Fellows & EPrints \\
\hline Institutional Repository@CSIO & EPrints \\
\hline IR@CECRI & EPrints \\
\hline IR@NPL & EPrints \\
\hline National Aerospace Laboratories Institutional Repository & EPrints \\
\hline NIRT Institutional Repository & EPrints \\
\hline Open Access Repository of IISc Research Publications & EPrints \\
\hline OpenMED@NIC & EPrints \\
\hline Sardar Vallabhbai National Institute of Technology EPrints & EPrints \\
\hline $\begin{array}{l}\text { University of Mysore - Digital Repository of Research, Innovation and } \\
\text { Scholarship (ePrints@UoM) }\end{array}$ & EPrints \\
\hline Indian Institute of Management Kozhikode Digital Library & Greenstone \\
\hline
\end{tabular}

Table:2 Institutional Repository in India listed by DOAR

\begin{tabular}{|c|c|c|c|}
\hline Software & $\begin{array}{c}\text { No of repositories use } \\
\text { Dspace/Eprints/GSDL }\end{array}$ & Percentage & Rank \\
\hline Dspace & 42 & 60.46 & 2 \\
\hline EPrints & 21 & 30.54 & 3 \\
\hline GSDL & 1 & 09.00 & 1 \\
\hline
\end{tabular}


The comparative study between dspace, eprints, and GSDL of the above table shows Dspace repository ranked in first position. The Dspace predominates in science and technology repositories in higher learning institutions.

\section{Findings}

There are 74 repositories listed in table 2. It was taken from DOAR, based on the table following conclusion as been drawn.

- Total number of repositories in India is 70

- Total number of repositories belongs to science and technology is 44

- Total number of IR belongs to multi-disciplinary subjects is 30

- $\quad$ Out of 74 repositories 42 Dspace, 21e-prints, and 1GSDL.

Therefore the study shows majority of higher learning institutions are using Dspace software used to establishing web based institutional repository in India.

\section{Interoperability}

Interoperability is the ability of two or more systems to exchange information and to use the information that has been exchanged. There are different kinds of different kinds of interoperability discussed such as technical interoperability, semantic interoperability, political Human interoperability, Inter-community interoperability, legal interoperability, international interoperability, However this article is more concerned with technical interoperability and search interoperability technical operability is all them hardware and software components of networks and information system can physically communicate and transfer information successfully whereas search interoperability is as the ability to perform a search over diverse set of metadata records and obtain meaningful results.

\section{Materials Included in the Repositories:}

Registered Research scholars and faculty members and students of AUTT may submit their documents to the IR. Each community has four distinct classes of collection:

- $\quad$ conference papers

- faculty publications

- $\quad$ project report and Theses

- Question papers/class lecture notes/convocation address/annual reports.

- E-books

\section{Submission process in IR:}

A new user must register in IR and became a member to submit the document in the repository. The following steps should follow for submitting the collection.

(i) Collection type

(ii) Content description by adding metadata and keywords

(iii) Upload the file

(iv) verification is done for submitting items

(v) Licence policy and IPR

\section{Chain process of submission:}

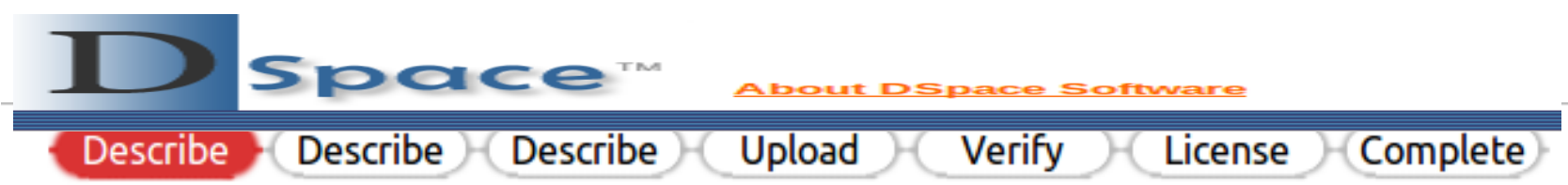

There are seven steps in submission process the first three steps are described about the collection. The fourth step shows the upload the collections. The fifth step verifies the collection allocate the location. The sixth step is licencing the document and the final steps gives a message that your collection is successfully submitted. 


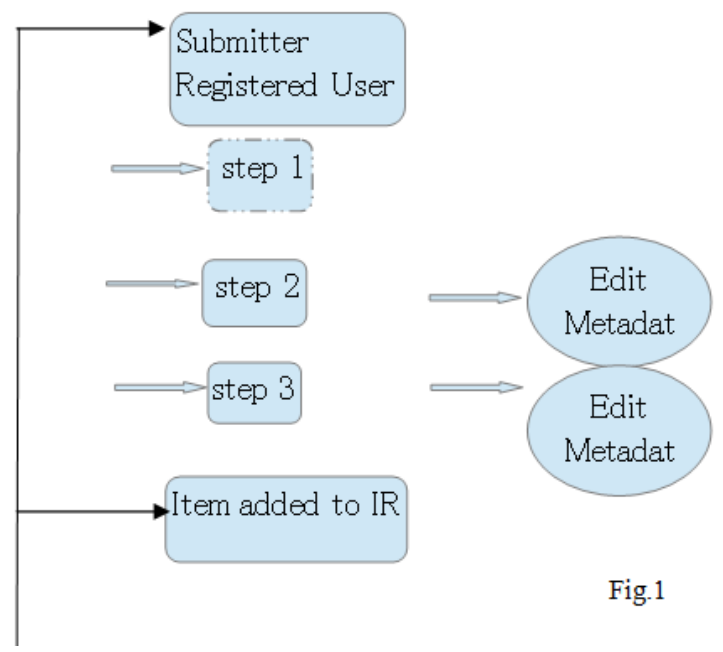

Hardware requirements:

The server specification for IR at AUTT is given below

\begin{tabular}{|c|c|}
\hline Specifications & Description \\
\hline Server & Dual CPU capable Xeon server \\
\hline $\mathrm{CPU}$ & Intel Xeon 3.6 GHZ, dual CPU \\
\hline System Bus & $800 \mathrm{MHZ}$ \\
\hline Cache & $1 \mathrm{MBL} 2$ \\
\hline Chipset & Intel E7520 \\
\hline Memory ECC DDR II & $\begin{array}{l}4 \mathrm{~GB}(4 \times 1 \mathrm{~GB}) \text { ECC DDR } 2 \text { SDRAM memory, memory mirroring and sparing should be } \\
\text { supported }\end{array}$ \\
\hline Memory slots & Eight DIMM slots \\
\hline HDD & $4 \times 146$ GB hot swappable ultra 320 wide SCSI HDD, $10,000 \mathrm{rpm}$, Seagate/Hitachi \\
\hline HDD bays & Eight hot swappable HDD bays \\
\hline SCSI controller & Dual channel: two Ultra 320/LVD channels with on-board RAID $0 \& 1$ \\
\hline RAID controller & Intel Chilito-2 dual channel RAID $0,1,5$, and 10 \\
\hline DAT drive & 36/72 GB (72e) HP sure store external DAT drive \\
\hline Monitor & 17" TFT LCD color monitor \\
\hline 1.44 MB FDD & Board 1.44 MB FDD \\
\hline Combo drive & Combo drive $(16 \times \mathrm{DVD}, 52 / 32 / 52 \times \mathrm{CD}$ writer $)$ \\
\hline Keyboard & 107 key keyboards \\
\hline Mouse & Optical mouse (five button) \\
\hline Ethernet & Dual Intel gigabit Ethernet controllers with teaming feature \\
\hline Graphics & ATI RAGE XL SVGA PCI video controller with $8 \mathrm{MB}$ of video memory. \\
\hline $\mathrm{I} / \mathrm{O}$ slots & $\begin{array}{l}3 \mathrm{PCI} \text { slots: two } 64 \mathrm{Bit} / 133 \mathrm{MHz} \text { (hot pluggable) and one } 64 \mathrm{Bit} / 100 \mathrm{MHz} \text { PCI express: one } 4 \times \\
\text { slots and one } \times 8 \text { slot (both should be hot pluggable) }\end{array}$ \\
\hline $\mathrm{I} / \mathrm{O}$ ports & 2 serial, 2 PS/2, 2 USB \\
\hline Power supply & $650 \mathrm{~W}$ redundant power supply $(1+1)$ \\
\hline Antivirus & Antivirus preloaded \\
\hline Operating system-licensed & Red hat enterprise Linux \\
\hline
\end{tabular}

Table.3

\section{Software requirements:}

In addition the other software was needed to run Dspace:

*Operating system Name: Linux (3.8.0-29 generic)

*Operating System Architecture: i386 
*Java 1.6

*Apache Ant 1.5 or later (java make-like tool)

*Postgre SQL 7.3 or later, an open source relational database and

Jakarta Tomcat $4 \times / 5 . \times$ or equivalent.

In addition to an acrobat PDF maker was acquired to convert MS document files to PDF.

\section{Intellectual Property and institutional repository:}

Intellectual Property for open access repositories of scholarly resources is simply over by the ease with which content can be copied and redistributed on the network. They are available to all free of cost at the point of use. It is those who create rather than those who consume control the scholarly communication process. It has been proved a useful adjunct to the published literature rather than a replacement for it and these are heavily used. Of course it depends on the data provides, and they may have to follow Intellectual property issues carefully so as to provide the service for a longer period of time.

\section{Conclusion:}

The study recommended that there is a need to establish institutional repository in higher learning institutions. Therefore, this article shows how to Establishing the Institutional repository in organizations to set up a resource centre to harvest data from their respective institutional repositories, particularly in web based higher learning institutions. The repository manager or otherwise the trained IR staff to take the responsibility of technical aspects to ensure proper harvestable metadata and its standards. It is required to encourage exchange of best practices and knowledge about the implementation and support of institutional repository, based on proper guidelines. It is a timely article to capture the resources instated of resource sharing. Today the higher learning institutions are independent to accumulate the advanced knowledge in higher education and reducing the resources sharing concept of traditional libraries. Every scholar is independent to develop his own web based digital library as per his/her convenience. It is known as boost to the micro digital libraries.

\section{References:}

[1]. Arunachalam, S.(2008) Open Access in India : Hopes and Frustrations. Retrieved from htpp://elpub.scix.net/data/works/att/271 elpub2008.content.pdf

[2]. Institutional repository checklist and resource guide 2006, SPARC International Repository available at:www.arl.org/sparc/IR

[3]. The value proposition in institutional repositories: Edu cause Review, Vol.40 No,5, pp.76-79.

[4]. Taylor \& Francis Open Retrieved May 4, 2012 from http://journal authors.tandf.co.uk/preparation/Open Access.asp

[5]. Zeng, M.L., \& Qin, j. (2008). Metadata. New York: Neal-Schuman Publishers, pp.15-84.

[6]. Johnson, Richard, Institutional Repositories: Partnering with Faculty to Enhance Scholarly Communication. "D-Lib Magazine, November, 2002

[7]. Dutta, B. (2010). Generating web based information services using sematic web repository, Pune university.

[8]. Rekha Mittal, G. Mahesh, (2008). Digital libraries and repositories in India: an evaluation study. Program: electronic library and information systems, 42(3),286-302

[9]. Prasad ARD, Open Source Digital Library Software, available at http://hdl.handle.net/1849/188

[10]. Downing, Jim, DSpace 2 Roadmap available at http://hdl.handle.net/1849/184

[11]. Lynch, Clifford, "Institutional Repositories: Essential Infrastructure for Scholarship in the Digital Age, "226, February 2003.

[12]. Branin, Joseph 'Institutional Repositories, “ Encyclopedia of Library and Information Science, May 2004.

[13]. http://en.wikipedia.org/wiki/Institutional_repository

[14]. http://www.opendoar.org

[15]. http://dspace.org

[16]. http://eprints.org 